\author{
Military Technical College \\ Kobry Elkobbah, Cairo, \\ Egypt.
}

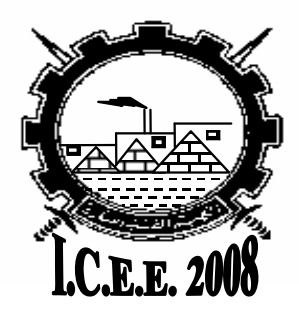

$4^{\text {th }}$ International Conference On Chemical \& Environmental Engineering 27-29 May 2008

\title{
PREPARATION AND CHARACTERIZATION OF SHEET EXPLOSIVES BASED ON HEXOGEN AND POLYISOBUTYLENE
}

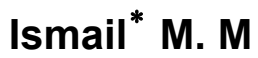

\begin{abstract}
The explosive material is the basic element of Explosive Reactive Armor (ERA) phenomenology. Here, initiation and detonation of such explosives are the decisive factors on which the performance of such armors depends. In the present work certain formulations of Plastic Bonded Explosives (PBX's) were prepared using the slurry technique. The prepared samples were kneaded with certain ingredients and subjected to rolling to produce sheets of PBX's. The obtained sheets were tested and characterized, by assessing their sensitivity to some mechanical and thermal stimuli. Also, the velocity of detonation was measured and some of the mechanical properties were determined. In addition, the samples were used in specific ERA modules, where standard shaped charges and bullet were fired against. For comparison, a selected type of sheet explosive was subjected to the same tests. Finally, A computer work was performed using a powerful computer code, the AUTODYN-2D, to model the behavior of such explosives under jet attack.

It was concluded that no significant difference was found between the prepared samples and the selected types of sheet explosives under jet attacks. Also, the behavior of the tested explosives under bullet impact was identical, where no initiation happened. In addition, A good agreement between the AUTODYN-2D hydrocode results and the experimental results was evident. Finally, it becomes evident that the prepared explosives demonstrated the same efficiency as the selected type of sheet explosives.
\end{abstract}

